\title{
Histomorphological Study to find out the Etio-pathogenesis of Appendicectomy Specimens - A Cross Sectional Study in RIMS, Ranchi
}

\author{
Dr.Utkrisht Kant ${ }^{1}$,Dr.Vinay Pratap ${ }^{2}$,Dr. Samir Toppo ${ }^{3}$. \\ ${ }^{I}$ Senior Resident, Department of General Surgery, Rajendra Institute of Medical Sciences, Ranchi. \\ ${ }^{2,3}$ Associate Professor, Department of General Surgery, Rajendra Institute of Medical Sciences, Ranchi.
}

\begin{abstract}
:
Introduction: Disease of the appendix looms large in surgical practice, but still there is controversy regarding the pathogenesis. The objective is to study the distribution of appendicitis and other appendiceal lesions according to age, sex and predominance, and to determine the etiopathogenesis behind it. In one year, 100 resected appendix specimens studied, those were clinically diagnosed as appendicitis.

Material and Method: Gross examination of the resected appendix specimens and microscopic examination by using routine and special stains.

Results: Among 100 cases, 70 chronic appendicitis, 13 acute appendicitis, 9 eosinophilic appendicitis, 3 granulomatous appendicitis, 1 enterobial appendicitis, mucocele, carcinoid, carcinoma and lymphoma each were observed. Female predominance is noted with 57 female and 43 male cases. The commonest age group is between 21 - 30 years. The commonest cause of luminal obstruction is faecolith.

Conclusion: Luminal obstruction by faecolith, lymphoid hyperplasia or increased fibrosis is the main cause behind the pathogenesis of appendicitis. The second probable cause is virus induced mucosal ulceration, followed by bacterial invasion.
\end{abstract}

Keywords: Chronic appendicitis, faecolith, mucosal ulceration, bacterial invasion..

\section{Introduction}

Developmentally the appendix is an underdeveloped residuum of the otherwise voluminous caecum. It is a narrow wormlike tubular diverticulum, which arises from the postero-medial wall of the caecum about $2 \mathrm{~cm}$ below the ileo-caecal junction, and is suspended by a peritoneal fold known as the mesoappendix. Though the appendix is a minute organ, its inflammation i.e. appendicitis is the commonest abdominal surgical emergency. Not only appendicitis, many other appendiceal conditions such as infection, parasitic infestation, tumors, diverticulosis, intussusception, torsion, endometriosis etc. are also known, some of them with prolonged morbidity and occasional mortality. Thus, disease of the appendix looms large in surgical practice. Not only for surgeons, the appendix is still a challenge for the pathologists as because the major pathogenic mechanism in the development of various appendiceal conditions has long been debated.We live in an era when criteria for histologic diagnoses are being analyzed, refined and subjected to the principles of evidence-based medicine. It seem surprising and somewhat ironic that the diagnosis and interpretation of various appendiceal conditions, remain poorly defined, subjected to misconceptions, and prone to variable terminology. These problems were the stimuli for the present study, a review of the histo-morphological findings and clinico-pathologic correlation in a series of appendices recently removed surgically in a teaching hospital at the Rajendra Institute of Medical Sciences, Ranchi with a large paediatric and adult patient population. It will also consider the epidemiology, etiopathogenesis and basic pathology of various conditions of the appendices, already removed surgicallyThe term appendicitis was introduced by R.H. Fitz of Boston, whose classic paper in 1886 first drew attention to the significance of acute inflammatory lesions of the appendix as sources of suppurative conditions in the right iliac fossa. ${ }^{1}$

It is supposed that acute appendicitis is predominantly a disease of the Western world. ${ }^{1}$ It is particularly common in Western Europe, North America and Australasia and rare in tropical Africa and India. But cases of acute appendicitis, is gradually increasing in India. The difference according to geographical location has been explained on the basis of dietary variance, the highest risk occurring when the diet is reduced in bulk with diminished cellulose and a high protein intake. According to various study groups, it has been suggested that appendicitis has its greatest frequency in the second and third decades of life. ${ }^{2}$ According to Foreign studies, acute appendicitis affects males and females about equally, ${ }^{3}$ but male predominance is found in majority of the Indian studies. ${ }^{4}$ Deaths from appendicitis are very rare, and usually occur in the elderly, in whom the symptoms are less striking in relation to the severity of the disease and in whom silent perforation of the appendix with peritonitis is more common. ${ }^{5}$ 
It is now generally considered that, obstruction of the lumen of the appendix is the most important initiating factor of acute appendicitis. ${ }^{4}$ The best recognized cause of luminal obstruction of acute appendicitis is a faecolith. ${ }^{6}$

\section{Materials And Methodology}

This cross-sectional study was carried out in the Department of General Surgery, Rajendra Institute of Medical Sciences, Ranchi. Specimens under study, were all those appendicectomy specimens referred to the Department of Pathology, Rajendra Institute of Medical Sciences, Ranchi for histopathological study.

Sample Size: A total number of 100 cases were included in the study.

Appendicectomy consists of the removal of the entire appendix after dividing the mesoappendix and ligation of the base of the appendix that connects to the caecum. At first, measurement of the organ was taken including the length and greatest diameter. It was followed by the examination of the external surface, whether it shows hyperemia, haemorrhage or perforation, or covered by fibrin or pus. If any localized lesion was identified, noted. After cutting the specimen for histological study, condition of the lumen whether it is obliterated or dilated and its contents (faecal matter, faecolith, pus etc.) were also noted. Condition of the mucosa, whether showing hyperemia or ulceration is important. Condition of the mesoappendix was also properly observed and noted.

\section{Results}

Statistical Analysis: The data was analyzed by using SPSS 20 software. The data is presented in percentages, rates and ratios. Chi square test was used to find the association between attributes.

Table - I: Distribution of Cases

\begin{tabular}{|c|c|c|}
\hline Cases & Number of Cases & Percentage \\
\hline Acute Appendicitis & 13 & 13 \\
\hline Chronic Appendicitis & 70 & 70 \\
\hline Eosinophilic Appendicitis & 9 & 9 \\
\hline Granulomatous Appendicitis & 3 & 3 \\
\hline Enterobial Appendicitis & 1 & 1 \\
\hline Mucocele & 1 & 1 \\
\hline Carcinoid & 1 & 1 \\
\hline Carcinoma & 1 & 1 \\
\hline Lymphoma & 1 & 100 \\
\hline Total & 100 & \\
\hline
\end{tabular}

Chronic appendicitis is the predominant appendiceal lesion found in our study, comprised of $70 \%$ of the total appendicectomy specimens received. Acute appendicitis and eosinophilic appendicitis is comparatively less in this region comprised of $13 \%$ and $9 \%$ of the total cases. Other appendiceal lesions observed showed less incidence.

Table - II: Age Wise Distribution

\begin{tabular}{|c|c|c|}
\hline Age (Years) & Number of Cases & Percentage \\
\hline $0-10$ & 01 & 1 \\
\hline $11-20$ & 25 & 25 \\
\hline $21-30$ & 42 & 42 \\
\hline $31-40$ & 20 & 20 \\
\hline $41-50$ & 6 & 6 \\
\hline $51-60$ & 4 & 4 \\
\hline$>60$ & 2 & 2 \\
\hline Total & 100 & 100 \\
\hline
\end{tabular}

The incidence of acute appendicitis is most common in the age group of 21-30 years, followed by 11-20 years.

Table - III: Sex Distribution

\begin{tabular}{|c|c|c|}
\hline Sex & Number of Cases & Percentage \\
\hline Male & 43 & 43 \\
\hline Female & 57 & 57 \\
\hline Total & 100 & 100 \\
\hline
\end{tabular}

Female predominance over the males is noted with F:M ratio of 1.33:1 in this study. We obtained 57 (57\%) female and $43(43 \%)$ male cases. 
Table - IV: Histological types of Chronic Appendicitis Observed.

\begin{tabular}{|c|c|c|}
\hline Types & Number of Cases & Percentage \\
\hline Obstructive & 58 & 82.86 \\
\hline Non-obstructive & 12 & 17.14 \\
\hline Total & 70 & 100 \\
\hline
\end{tabular}

Grossly, majority of the resected appendix specimens showed congested serosal vessels and presence of faecolith in the lumen. Half of the cases showed thickened wall on cut section. Chronic appendicitis showing luminal obstruction is the predominant variety than chronic appendicitis without obstruction of the lumen.

Table - V: Observation table for 58 Obstructive Chronic Appendicitis cases

\begin{tabular}{|c|c|c|}
\hline Observation & Number of Cases & Percentage \\
\hline Faecolith & 15 & 25.86 \\
\hline Fat and fibrosis & 10 & 17.24 \\
\hline Lymphoid hyperplasia & 7 & 12.07 \\
\hline Combination of the above & 26 & 44.83 \\
\hline Total & 58 & 100 \\
\hline
\end{tabular}

58 total cases of obstructive chronic appendicitis observed. 15 cases showed obstruction of the lumen by faecolith, 10 cases showed narrowing or obliteration of the lumen by fat and fibrosis and 7 cases showed almost complete obliteration of the lumen by lymphoid hyperplasia. But majority of cases (26 cases) showed narrowing of the lumen or complete obliteration of the lumen by the co-existence or combination of the above causes.

\section{Discussion}

Literature suggested that, in $19.1 \%$ of cases, surgeons missed the diagnosis of acute appendicitis and in $7.82 \%$ of cases, surgeons misinterpreted a normal appendix or an appendix with periappendicitis as acute appendicitis. ${ }^{7}$ In another study, it was observed that, in $5 \%$ of cases important pathological findings were found incidentally; thus making routine evaluation unavoidable. ${ }^{4}$

In the present study, we took up microscopic evaluation of all appendicectomies those are clinically diagnosed as appendicitis.

Age Distribution: Different studies have quoted the commonest age group for appendicitis to be 2 nd and 3rd decades. ${ }^{1}$ In our study the most susceptible age group is 21-30 years which correlates with majority of the studies. We have found that 42 cases (42\%) were between 21-30 years of age group. The next susceptible age group is $11-20$ years, having 25 cases $(25 \%)$. The incidence of appendiceal lesions are minimum in both extremes of life.

Sex Distribution: In various studies, sex ratio of patients undergoing appendicectomy showed male predominance. ${ }^{8}$ However, in our study female predominance over the males is noted with M:F ratio of 1:1.33, which does not correlate with most of the other studies. We got 57 cases of female and 43 male cases. Most probably the reason behind female predominance is increased laparoscopic intervention in the pelvic and lower abdominal region of the females now a days.

Chronic Appendicitis: As this entity has been recognized by some authors and not by all, the criteria have differed from study to study. However, using our criteria as given by Dr. Juan Rosai ${ }^{9}$, that the presence of chronic inflammation in the muscle layers should be considered as chronic appendicitis, we found that chronic appendicitis is the commonest appendiceal lesion in this region occupying the major bulk of the sample size in this study, i.e. 70 cases $(70 \%)$. This finding does not correlate with the other study. ${ }^{8}$

In this study we evaluated obstructive and non-obstructive chronic appendicitis cases. On microscopic examination, obstructive chronic appendicitis is found as the commonest variety with 58 cases $(82.86 \%)$ followed by nonobstructive variety, 12 cases (17.14\%). The first single most dominant cause of luminal obstruction is the presence of faecal matter or faecolith. $25.86 \%$ of the total obstructive chronic appendicitis cases showed presence of faecolith. This finding correlates with the other study. ${ }^{2}$

It has been stated that, complete obstruction of the lumen by faecolith increases the presence of secretions in the obstructed lumen, resulting ischaemic damage to the mucosa, allowing invasion of the wall of the appendix by faecal organisms and consequent inflammation. ${ }^{9}$

\section{Conclusion}

Appendicitis is the commonest appendiceal lesion and chronic appendicitis is the predominant variety in this region occupying $70 \%$ of the total cases studied. The commonest age group for appendicitis is between 21 - 30 years. Majority of the chronic appendicitis cases $(82.86 \%)$ showed luminal obstruction and faecolith or solid faecal matter is the single most dominant cause of luminal obstruction. This finding support the luminal obstruction hypothesis as the etiology. 


\section{References}

[1]. Carr NJ. The Pathology of Acute Appendicitis. Ann Diagn Pathol 2000; 4(1) : 46-58

[2]. Morson BC. Systemic Pathology (Alimentary tract). 3rd Ed. Edinb: Churchill Livingstone; 1987.

[3]. Kumar V, Abbas AK, Fausto N. Robins and Cotran Pathologic Basis of Disease. 7th Ed. New Delhi: Thomson Press; 2004.

[4]. Gupta SC, Gupta AK, Keswani NK, Singh PA, Tripathi AK, Krishna V. Pathology of tropical appendicitis. J Clin Pathol 1989; 42: 1169-72.

[5]. Virmani S, Dawar R, Sushma, Palankar N, Govil D. Clinical presentation of acute appendicitis. Gastroenterol Today. 2004 July Sept; VIII (3): 117-8

[6]. Butler C. Surgical Pathology of acute appendicitis. Hum Pathol 1981; 12(10): 870-8.

[7]. Lau W, Fan S. Yiu T. The clinical significance of routine histopathologic study of the resected appendix and safety of appendiceal inversion. Surg Gynecol Obstet 1986; 162: 256-8.

[8]. Naik PC, Pradhan AK, Mohanty SK. Evaluation of causes of appendicitis on the basis of operative and histopathological findings. The antiseptic 2005 Sept.; 102(9): 537-539.

[9]. Rosai J. Rosai and Ackerman's Surgical Pathology. 9th Ed. St. Louis: Mosby; 2004 